Check for updates

Cite this: RSC Adv., 2017, 7, 24723

Received 21st March 2017

Accepted 24th April 2017

DOI: $10.1039 / \mathrm{c} 7 \mathrm{ra03330c}$

rsc.li/rsc-advances

\section{Maleic anhydride-allylpolyethoxy carboxylate copolymer as an effective and environmentally benign inhibitor for calcium carbonate in industrial cooling systems}

\author{
Guangqing Liu, (D) *ab Mengwei Xue, ${ }^{a}$ Qinpu Liu, ${ }^{a}$ Hui Yang, ${ }^{a}$ Jingjing Yang ${ }^{a}$ \\ and Yuming Zhou ${ }^{b}$
}

For the control of calcium carbonate scales, a novel environmentally friendly type of scale inhibitor ML $n$ was synthesized. The structure and thermal property of ML15 were characterized and measured by FT-IR, ${ }^{1} \mathrm{H}$ NMR, TGA and GPC. The anti-scale property of the $\mathrm{MLn}$ copolymer towards $\mathrm{CaCO}_{3}$ in the artificial cooling water was studied through static scale inhibition tests, the observation shows that $\mathrm{CaCO}_{3}$ inhibition increase with increasing the degree of polymerization of $\mathrm{MLn}$ from 5 to 15 , and the dosage of $\mathrm{MLn}$ plays an important role on $\mathrm{CaCO}_{3}$ inhibition. The effect on formation of $\mathrm{CaCO}_{3}$ was investigated with combination of scanning electronic microscopy (SEM) and X-ray powder diffraction (XRD) analysis. Inhibition mechanism is proposed that the interactions between calcium and polyethylene glycol (PEG) are the fundamental impetus to restrain the formation of the scale in cooling water systems.

\section{Introduction}

Open recirculating cooling water systems are frequently used because they not only provide economical heat removal but also recirculation of water conservation is accomplished with substantial cost reductions. The cooling water circulates to operating units where it picks up heat and the resulting warm water is cooled through vaporization by returning to the cooling tower. Dissolved and suspended matter contained in the water is concentrated in cooling water recirculation. The precipitation of calcium carbonate and calcium sulphate scale on heat transfer surfaces widely occurs, which involves the deposition of an insulating layer onto the internal walls owing to its inverse temperature-solubility characteristics. ${ }^{1,2}$ Deposits formation may cause severe corrosion and deterioration of heat exchange. The study of the mechanism of calcium carbonate crystal growth inhibition is an important theme for developing an effective technique to prevent scale formation. The most common and effective method of scale controlling is the use of chemical additives as scale inhibitors that retard or prevent scale formation even in very small concentrations. ${ }^{3}$ Several studies about calcium carbonate scale formation in the absence and presence of inhibitors have been carried out. ${ }^{4-9}$

${ }^{a}$ School of Environmental Science, Nanjing Xiaozhuang University, Nanjing 211171, $P$. R. China. E-mail: 0539liuguangqing@163.com; Tel: +86-25-86178263

${ }^{b}$ School of Chemistry and Chemical Engineering, Southeast University, Nanjing 211189, P. R. China
Copolymer has been used satisfactorily as a specific scale inhibitor in the circulating cooling water systems is developed in the late 1970s because of its strong complexation of multifunctional groups and superior dispersion characteristic of macromolecule. ${ }^{10}$ This kind of chemical inhibitors is applied widely in circulating cooling water treatment contribute to their excellent performances such as inhibiting formation of calcium carbonate, calcium sulphate, calcium phosphate scale. In addition, some of them can perform as a metal corrosion inhibitor. With the improvement of environmental consciousness, the content of phosphorus in water treatment agent has been of rigorous control. Concerning over accelerated aquatic eutrophication, the popularity of inhibitors containing high phosphorus is diminishing. As a result, the current trend for inhibitor usage is toward more environmentally friendly "green" chemicals. On the other hand, the design or optimization of the recycling-water process on an industrial scale demands a thorough understanding of all the fundamental parameters that govern the various operations involved. Therefore, the inhibition varying with the solution $\mathrm{pH}, \mathrm{Ca}^{2+}, \mathrm{HCO}_{3}{ }^{-}$and $\mathrm{Fe}^{2+}$ concentration should be tested.

In the present work, we try to discover and explore the effectiveness of a structurally well-defined calcium carbonate antiscalant which is phosphorus free and has a superior calcium tolerance. Inhibitor employed in this paper is doublehydrophilic block copolymer of maleic anhydride (MA)-allylpolyethoxy carboxylate (APEL $n$ ). 


\section{Materials and methods}

\subsection{Materials}

APEL $n$ was synthesized from allyloxy polyethoxy ether (APEGn) in our laboratory according to L.Ling. ${ }^{11} \mathrm{MA}$ is analytically pure grade and was supplied by Zhongdong Chemical Reagent Co. (Nanjing, Jiangsu, China). Distilled water was used for all the studies.

Fourier-transform infrared (FT-IR) spectra were taken on a Bruker FT-IR analyzer (VECTOR-22, Bruker Co., Germany) by using the KBr-pellet method (compressed powder). ${ }^{1} \mathrm{H}$ NMR spectra were recorded on a Mercury VX-500 spectrometer (Bruker AMX500) using tetramethylsilane (TMS) internal reference and deuterated dimethyl sulfoxide (DMSO-d6) as a solvent. Thermogravimetric analysis (TGA) was performed on samples at temperatures ranging from $25{ }^{\circ} \mathrm{C}$ to $600{ }^{\circ} \mathrm{C}$. Such signals were obtained at a heating rate of $20{ }^{\circ} \mathrm{C} \mathrm{min}^{-1}$ in air using a PerkinElmer Derivatograph instrument. Molecular weight of the polymers was investigated through gel permeation chromatography (GPC-Waters-2410). The X-ray diffraction (XRD) patterns of the $\mathrm{CaCO}_{3}$ crystals were recorded on a Rigaku D/max $2400 \mathrm{X}$ ray powder diffractometer with $\mathrm{Cu} \mathrm{K} \alpha(\lambda=1.5406)$ radiation (40 $\mathrm{kV}, 120 \mathrm{~mA}$ ). Powder samples were mounted on a sample holder and scanned at a scanning speed $2^{\circ} \mathrm{min}^{-1}$ between $2 \theta=20-60^{\circ}$. The shape of calcium carbonate scale was observed with a scanning electron microscope (S-3400N, HITECH, Japan).

\subsection{Synthesis of MA-APELn}

A 5-neck round bottom flask, equipped with a thermometer and a magnetic stirrer, was charged with $90 \mathrm{~mL}$ distilled water and 0.1 mol APEL5 and heated to $70{ }^{\circ} \mathrm{C}$ with stirring under nitrogen atmosphere. After that, $1.0 \mathrm{~mol} \mathrm{MA}$ in $18 \mathrm{~mL}$ distilled water (the mole ratio of APEL and MA was $1: 10$ ) and the initiator solution (1.0 $\mathrm{g}$ ammonium persulfate in $18 \mathrm{~mL}$ distilled water) were added separately at constant flow rates over a period of $1.5 \mathrm{~h}$. The reaction was then heated to $80{ }^{\circ} \mathrm{C}$ and maintained at this temperature for an additional $2.5 \mathrm{~h}$, ultimately affording an aqueous polymer solution containing approximately $35 \%$ solid. Only 0.1 mol APEL5 was changed to $0.1 \mathrm{~mol}$ APEL10 or APEL15, and the rest of the synthesis experiment of MA-APEL5 was invariable, the product of MA-APEL10 or MA-APEL15 was obtained, respectively. MAAPEL5, MA-APEL10 and MA-APEL15 collectively called MLn ( $n=$ $5,10,15)$. The synthesis of $\operatorname{ML} n(n=5,10,15)$ is given in Scheme 1 .

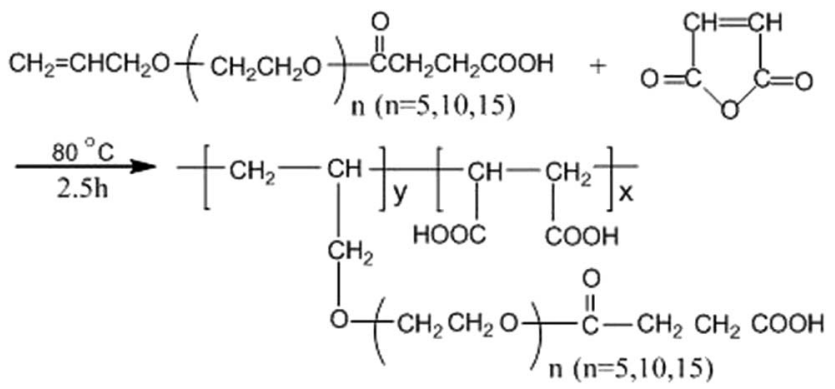

Scheme 1 Synthesis of $\operatorname{ML} n(n=5,10,15)$.

\subsection{Precipitation conditions}

The ability of the MLn copolymer to inhibit calcium carbonate scale was compared with that of the free-inhibitor in flask tests. The inhibitor dosages given are on dry-inhibitor basis. Calcium carbonate precipitation and inhibition were studied in artificial cooling water which was prepared by dissolving a certain quantity of $\mathrm{CaCl}_{2}$ and $\mathrm{NaHCO}_{3}$ in deionized water. Two concentrations of $\mathrm{Ca}^{2+}$ and $\mathrm{HCO}_{3}{ }^{-}$were $250 \mathrm{mg} \mathrm{L}{ }^{-1}$. The artificial cooling water containing different quantities of the MLn copolymer was thermostated at $60{ }^{\circ} \mathrm{C}$ for $10 \mathrm{~h}$. Calcium chloride and sodium bicarbonate used to prepare the scaling test solution were of analytical reagent grade. The phosphorous free and non-nitrogen copolymer had been synthesized in the laboratory.

Solution was analyzed after every set of experiments with respect to soluble calcium ions using a standard solution of EDTA according to standard methods. ${ }^{12}$ Inhibitor efficiency as a calcium carbonate inhibitor was calculated by using the following equation:

$$
\text { Inhibition }(\%)=\frac{\left[\mathrm{Ca}^{2+}\right]_{\text {final }}-\left[\mathrm{Ca}^{2+}\right]_{\text {blank }}}{\left[\mathrm{Ca}^{2+}\right]_{\text {initial }}-\left[\mathrm{Ca}^{2+}\right]_{\text {blank }}} \times 100 \%
$$

where $\left[\mathrm{Ca}^{2+}\right]_{\text {final }}$ is concentration of $\mathrm{Ca}^{2+}$ ions in the filtrate in the presence of inhibitor after calcium carbonate supersaturated solutions were heated for $10.0 \mathrm{~h}$ at $60{ }^{\circ} \mathrm{C},\left[\mathrm{Ca}^{2+}\right]_{\text {blank }}$ is concentration of $\mathrm{Ca}^{2+}$ ions in the filtrate in the absence of inhibitor after calcium carbonate supersaturated solutions were heated for $10.0 \mathrm{~h}$ at $60{ }^{\circ} \mathrm{C}$, and $\left[\mathrm{Ca}^{2+}\right]_{\text {initial }}$ is concentration of $\mathrm{Ca}^{2+}$ ions at the beginning of the experiment.

\section{Results and discussion}

\subsection{Characterization of copolymer}

The FT-IR spectra of APEG15, APEL15, and ML15 are exhibited in Fig. 1. The $1736 \mathrm{~cm}^{-1}$ strong intensity absorption peak $(-\mathrm{C}=$ O) in curve b reveals clearly that APEL15 has been synthesized successfully. The fact that the $(-\mathrm{C}=\mathrm{C}-)$ stretching vibration at $1646 \mathrm{~cm}^{-1}$ appears in curve b but disappears completely in

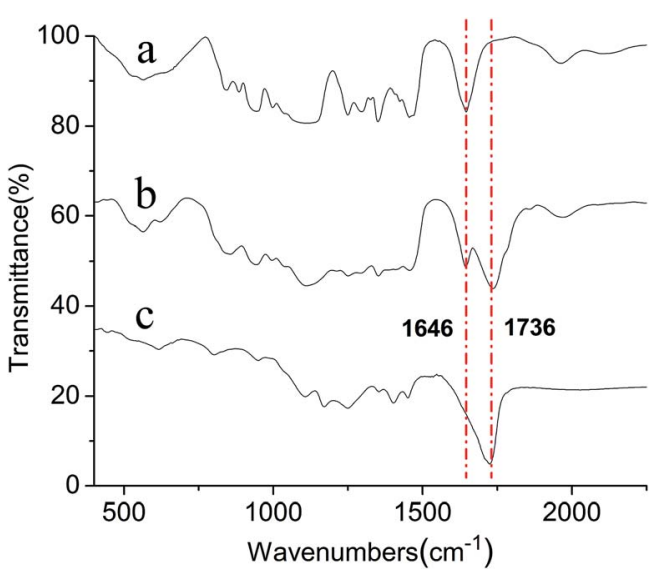

Fig. 1 The FT-IR spectra of APEG15 (a), APEL15 (b) and ML15 (c). 
curve $\mathrm{c}$ reveals that free radical polymerization between APEL15 and MA has happened.

APEG15 $\left(\left(\mathrm{CD}_{3}\right)_{2} \mathrm{SO}, \delta \mathrm{ppm}\right): 2.50$ (solvent residual peak of $\left.\left(\mathrm{CD}_{3}\right)_{2} \mathrm{SO}\right), 3.00-3.80$ (- $\mathrm{OCH}_{2} \mathrm{CH}_{2}-$, ether groups), 3.80-6.00 $\left(\mathrm{CH}_{2}=\mathrm{CH}-\mathrm{CH}_{2}-\right.$, propenyl protons), 4.40-4.60 (-OH, active hydrogen in APEG). [Fig. 2(a)].

APEL15 (( $\left.\left.\mathrm{CD}_{3}\right)_{2} \mathrm{SO}, \delta \mathrm{ppm}\right): 2.25-2.55\left(-\mathrm{CH}_{2} \mathrm{CH}_{2}-\right.$, protons in $-\mathrm{COCH}_{2} \mathrm{CH}_{2} \mathrm{COOH}$ ), 2.50 (solvent residual peak of $\left(\mathrm{CD}_{3}\right)_{2} \mathrm{SO}$ ), 3.00-3.80 (- $\mathrm{OCH}_{2} \mathrm{CH}_{2}-$, ether groups), 3.80-4.10 and 5.00-6.00 $\left(\mathrm{CH}_{2}=\mathrm{CH}-\mathrm{CH}_{2}-\right.$, propenyl protons). [Fig. 2(b)].

The $\delta$ 4.40-4.60 ppm (-OH) active hydrogen in (a) disappeared completely and $\left(-\mathrm{CH}_{2} \mathrm{CH}_{2}^{-}\right)$protons in $-\mathrm{COCH}_{2} \mathrm{CH}_{2}$ $\mathrm{COOH}$ appears obviously in $\delta$ 2.25-2.55 ppm in (b). It proves that $-\mathrm{OH}$ in APEG15 has been entirely replaced by $-\mathrm{COCH}_{2} \mathrm{CH}_{2} \mathrm{COOH}$.

ML15 (( $\left.\left.\mathrm{CD}_{3}\right)_{2} \mathrm{SO}, \delta \mathrm{ppm}\right): 2.50$ (solvent residual peak of $\left.\left(\mathrm{CD}_{3}\right)_{2} \mathrm{SO}\right), 3.00-3.80$ (-OCH $\mathrm{OCH}_{2}$, ether groups). [Fig. 2(c)].

$\delta$ 3.80-6.00 ppm in (b) double bond absorption peaks completely disappeared in (c). This reveals that free radical polymerization among APEL15 and MA has happened. From FT-IR and ${ }^{1} \mathrm{H}$-NMR analysis, it can conclude that synthesized ML15 has anticipated structure.

Thermogravimetric analysis (TGA) was used to obtain further information on the structures of APEG15, APEL15 and ML15. The corresponding TGA are depicted in Fig. 3. The figure shows that degradation of APEG15, APEL15 and ML15 all proceeded in
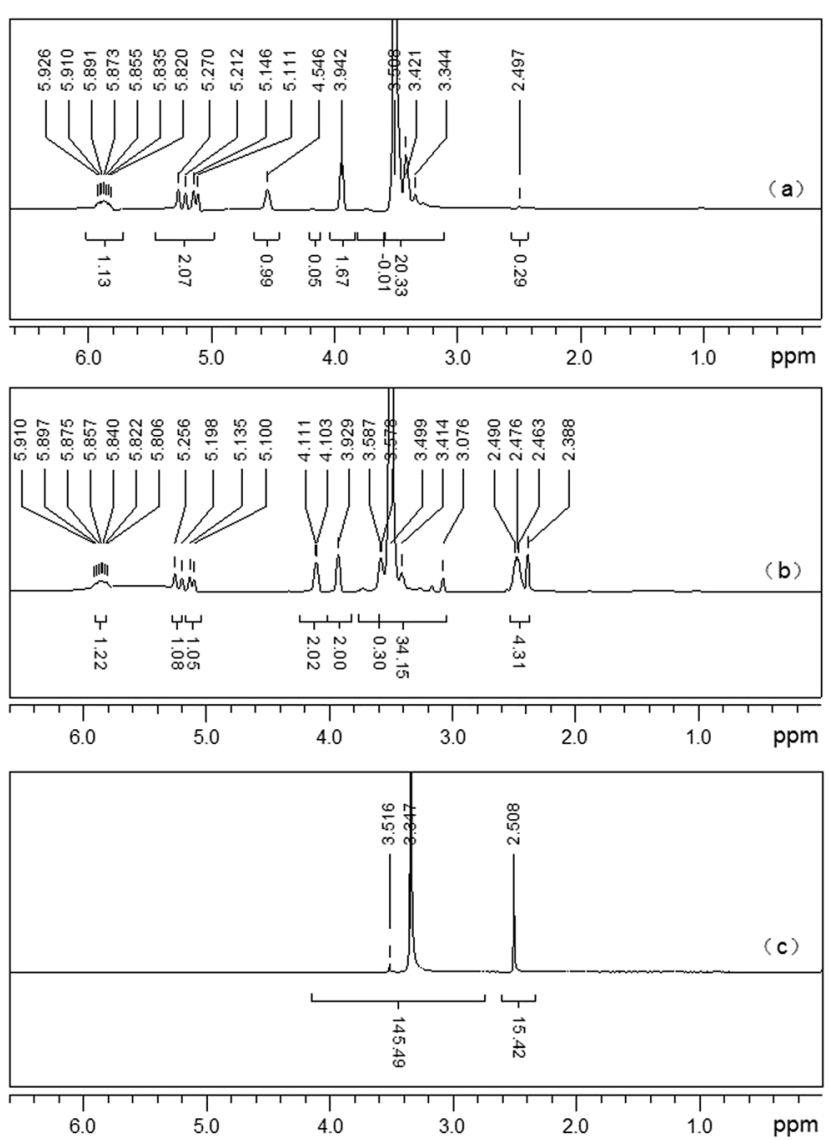

Fig. $2{ }^{1} \mathrm{H}$-NMR spectra of APEG15 (a), APEL15 (b) and ML15 (c). three or four stages. The first decomposition stage was assigned in the removal of the volatile matter present in these samples, such as entrapped moisture or extraction solvent. The greatest percentage decomposition of APEG15 and APEL15 occurred in the second stage $\left(150-430{ }^{\circ} \mathrm{C}\right)$, as indicated by the corresponding weight loss values (Fig. $3 \mathrm{a}$ and $\mathrm{b}$ ). It may be attributed to cracking and gasification at high temperatures. It is indicated that free radical polymerization can effectively enhance thermal stability of copolymer (Fig. 3c).

Molecular weight of the copolymers was investigated through gel permeation chromatography and the results are listed in Table 1 . Their molecular weights are less than $1 \times 10^{5}$. Low molecular weight is an essential parameter for efficient scale inhibition which is achieved through careful control of reaction rate and timely termination of chain propagation. The polydispersity index (PDI) was in range from 1.07 to 1.25 , which strongly suggests that the monomers satisfactorily undergo copolymerization to produce uniform copolymers.

\subsection{Influence of $\operatorname{MLn}(n=5,10,15)$ dosage on calcium carbonate inhibition}

The dosage of MLn $(n=5,10,15)$ has a strong effect on the formation of calcium carbonate precipitation, which was investigated and shown in Fig. 4. For example at $2 \mathrm{mg} \mathrm{L}^{-1}$ dosage, the polymers show poor calcium carbonate inhibition $(10.6,12.0$ and $14.3 \%$ for ML5, ML10, ML15, respectively). However, at $8 \mathrm{mg} \mathrm{L}^{-1}$, the performance of the polymers is substantially improved and maximum inhibitory power is obtained. It should be noted that the similar tendency of the dosage on the performance behavior has been reported in earlier studies by polymeric threshold inhibitors. ${ }^{11,13}$ The data in Fig. 4 show that $\operatorname{ML} n(n=5,10,15)$ are extremely effective in preventing the precipitation of calcium carbonate from aqueous solutions. Compared to the copolymer of ML5 or ML10, the copolymer of ML15 is superior against calcium carbonate scale. The reason can be attributed to ML15 copolymer containing longer polyethylene glycol (PEG) chain. Another reason is ML5 or ML10 has low molar mass (10 365 and 14227 for ML5 and ML10, respectively); but ML15 has high molar mass $\left(M_{\mathrm{w}}=21879\right)$. The results come to the conclusion that ML15 copolymer have the optimum molecular weight range.

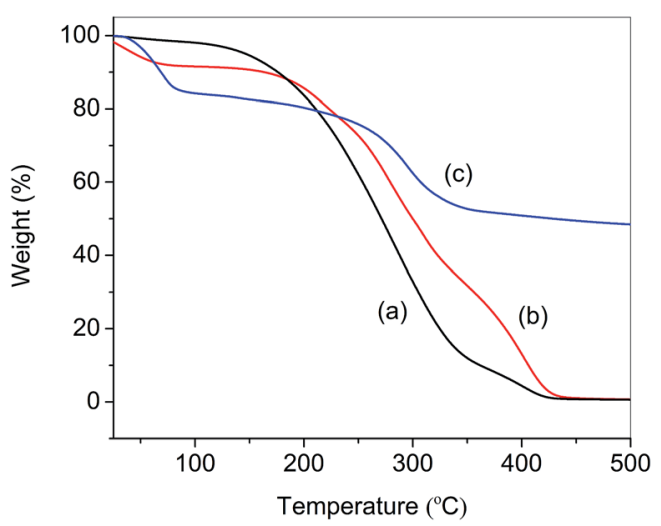

Fig. 3 TGA thermograms of APEG15 (a), APEL15 (b) and ML15 (c). 
Table 1 Molecular weight and polydispersity index (PDI) of the polymers

\begin{tabular}{llll}
\hline Copolymers & ML5 & ML10 & ML15 \\
$M_{\mathrm{w}}$ & 10365 & 14227 & 21879 \\
PDI & 1.19 & 1.25 & 1.07
\end{tabular}

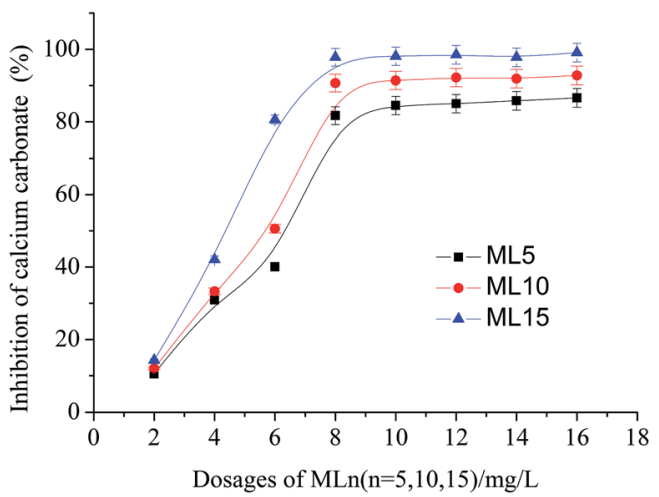

Fig. 4 Inhibition rate on calcium carbonate precipitation in the presence of varying dosages of $\operatorname{ML} n(n=5,10,15)$.

\subsection{Influence of solution property}

Solution properties have a great influence on the precipitation of calcium carbonate. In order to optimize parameters of the recycling water process on an industrial scale, we investigated the effect of the solution parameters on the calcium carbonate inhibition of ML15. The results are shown in Fig. 5 as follows:
Fig. 5a indicates ML15 provides unexceptionable calcium carbonate inhibition under conditions of water with a much higher hardness $\left(\mathrm{HCO}_{3}{ }^{-}\right.$concentration kept constant and at $732 \mathrm{mg} \mathrm{L}^{-1}$ level). Fig. 5b clearly demonstrates that with $\mathrm{HCO}_{3}{ }^{-}$ concentration increased $\left(\mathrm{Ca}^{2+}\right.$ concentration kept constant and at $240 \mathrm{mg} \mathrm{L}^{-1}$ level), ML15 polymers also possess excellent calcium carbonate inhibition. As illustrated in Fig. $5 \mathrm{c}$, calcium carbonate inhibitory power drops $29.1 \%$ with increasing the solution $\mathrm{pH}$ from 7 to 12 . The reason is probably that the solubility of calcium carbonate decreases when increasing the $\mathrm{pH}$. At a $\mathrm{pH}$ of 8.0-9.5, the usual $\mathrm{pH}$ values of the industry recycling water, ML15 still shows superior calcium carbonate inhibition. Thus, the incorporation of the high performance scale inhibitor ML15 into recycling water ensures a better overall system performance.

In consideration of the favorable reaction with iron ions, some antiscalants, such as PMA, would lose most of their effectiveness against calcium carbonate scale in the presence of traceamounts of iron in solutions. ${ }^{14}$ The results in Fig. $5 \mathrm{~d}$ show ML15 still has excellent calcium carbonate inhibition at levels of $2-10 \mathrm{mg} \mathrm{L}^{-1}$ iron ions in supersaturated solutions of calcium carbonate. However, the calcium carbonate inhibition of ML15 decreases dramatically at levels of $12-14 \mathrm{mg} \mathrm{L}^{-1}$ iron ions, and ML15 is totally ineffective against the calcium carbonate scale when the concentrations of iron ions in solutions are $14 \mathrm{mg} \mathrm{L}^{-1}$. The trace amounts of iron are usually on the order of 1-5 $\mathrm{mg} \mathrm{L}^{-1}$ in industrial recycling water systems, hence, the copolymer of ML15 is still a excellent antiscalant for calcium carbonate inhibition, even in the presence of trace amounts iron ions in aqueous solutions.
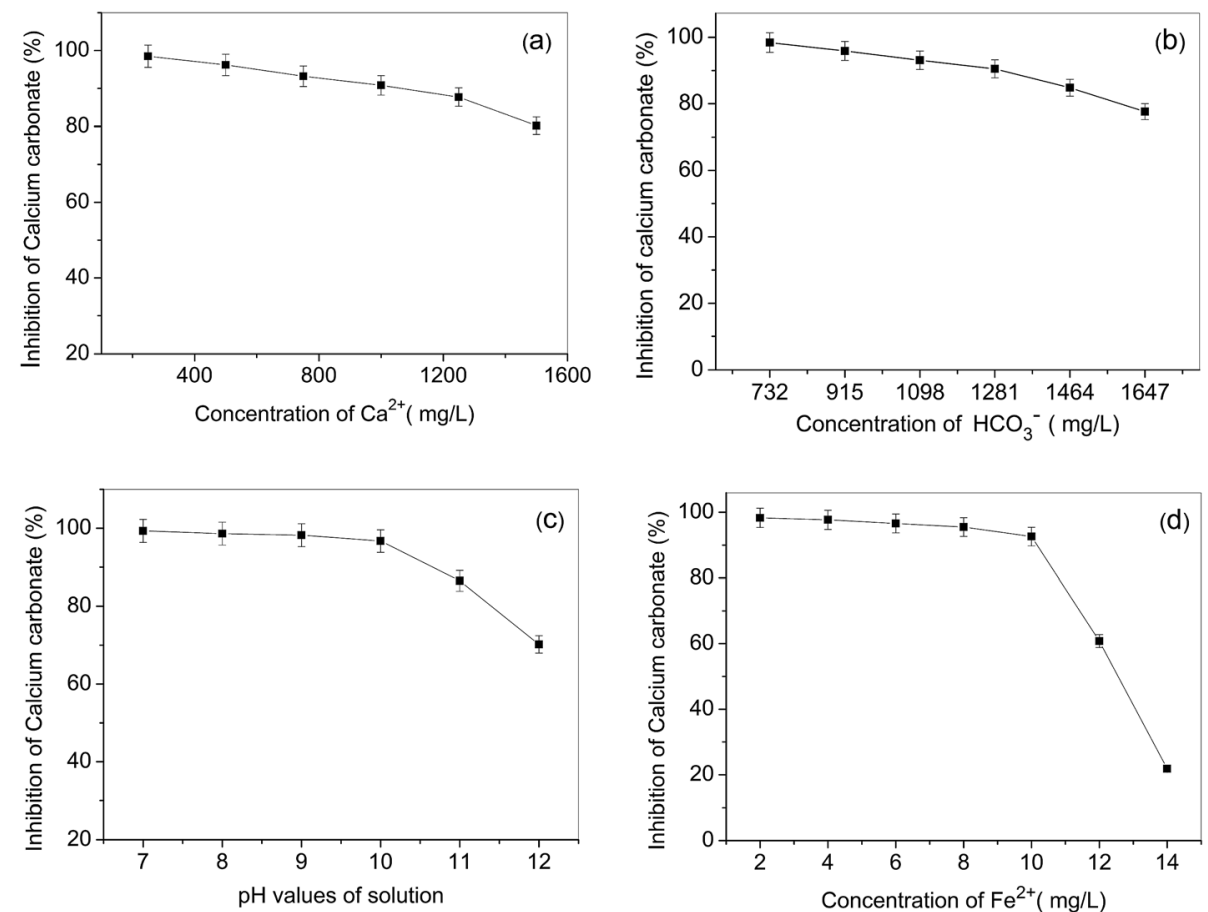

Fig. 5 Inhibition at a level of $8 \mathrm{mg} \mathrm{L}{ }^{-1} \mathrm{ML15}$ as a function of solution $\mathrm{Ca}^{2+}$ concentration (a), $\mathrm{HCO}_{3}{ }^{-}$concentration (b), $\mathrm{pH}$ (c), and Fe ${ }^{2+}$ concentration (d). 
Water cooling systems contains several ions, in order to take into account the interaction of these ions. We investigated the effect of $\mathrm{Ca}^{2+}, \mathrm{Mg}^{2+}, \mathrm{CO}_{3}{ }^{2-}, \mathrm{SO}_{4}{ }^{2-}$ and $\mathrm{PO}_{4}{ }^{3-}$ ions on the calcium scales inhibition of ML15. The data in Table 2 show that, under the experimental conditions of $240 \mathrm{mg} \mathrm{L}^{-1} \mathrm{Ca}^{2+}, 732 \mathrm{mg} \mathrm{L}^{-1}$ $\mathrm{CO}_{3}{ }^{2-}, \mathrm{pH} 9.0,80{ }^{\circ} \mathrm{C}$, and $8 \mathrm{mg} \mathrm{L}{ }^{-1}$ antiscalants, when the concentrations of $\mathrm{Mg}^{2+}, \mathrm{PO}_{4}{ }^{3-}$ and $\mathrm{SO}_{4}{ }^{2-}$ ions in solutions are below $50 \mathrm{mg} \mathrm{L}^{-1}, 50 \mathrm{mg} \mathrm{L}^{-1}$ and $500 \mathrm{mg} \mathrm{L}^{-1}$, respectively. The inhibition of scale formation was above $90 \%$. When the concentrations of $\mathrm{Mg}^{2+}, \mathrm{PO}_{4}{ }^{3-}$ and $\mathrm{SO}_{4}{ }^{2-}$ ions in solutions are $60 \mathrm{mg} \mathrm{L}^{-1}, 60 \mathrm{mg} \mathrm{L}^{-1}$ and $1000 \mathrm{mg} \mathrm{L}^{-1}$, respectively. The inhibitory value obtained for ML15 is $89.2 \%$. The results indicate that the interaction of these ions have the ability to affect the inhibition of scale formation to an extent. However, the inhibition of scale formation was still above $80 \%$ when the concentrations of $\mathrm{Mg}^{2+}, \mathrm{PO}_{4}{ }^{3-}$ and $\mathrm{SO}_{4}{ }^{2-}$ ions in solutions are $100 \mathrm{mg}$ $\mathrm{L}^{-1}, 100 \mathrm{mg} \mathrm{L}^{-1}$ and $2000 \mathrm{mg} \mathrm{L}^{-1}$, respectively.

\subsection{Comparisons of inhibition efficiency}

Furthermore, to understand the performance of ML15 copolymer scale inhibitor, some inhibition experiments were conducted with commercial inhibitors (T-225, HPMA, PAA, PESA) which was supplied by Zhongdong Chemical Reagent Co. (Nanjing, Jiangsu, China). Compared to these "green" inhibitors (Table 3), ML15 had superior ability to inhibitor the $\mathrm{CaCO}_{3}$ scale, with $97.8 \%$ inhibition at a level of $8 \mathrm{mg} \mathrm{L}^{-1}$, whereas it is $74.5 \%$ for PESA at the same dosage (the best inhibitor among them). So when compared to these nonphosphorus inhibitors, $\mathrm{CaCO}_{3}$ inhibition of ML15 is much better than that of PESA, T225, HPMA, PAA at the same dosage. It can be shown that the order of preventing the precipitation from flask tests was ML15 $>$ PESA $>$ T-225 > PAA $\approx$ HPMA.

Also, we can found that PAA and HPMA containing carboxyl groups and possessing molecular structure to ML15 inhibitor but can hardly control $\mathrm{CaCO}_{3}$ scale even at a high dosage. It may be that the side-chain polyethylene (PEG) segments of APEL $n$ and carboxyl groups of MA might play an important role during the control of calcium carbonate scales. Taking Table 3 into account, it can conclude that the studied copolymer ML15 not only to solve the water eutrophication problems caused by phosphorus but also because of its significant inhibition efficiency in cooling water systems.

We had compared with other non-phosphorus $\mathrm{CaCO}_{3}$ inhibitor in cooling water systems. Ling $e$ t al. had been reported a green $\mathrm{CaCO}_{3}$ inhibitor (PAA/APEG-PG-COOH), but PAA/ APEG-PG-COOH only showing approximately $80 \%$ inhibition. ${ }^{11}$
Table 3 Comparison of $\mathrm{CaCO}_{3}$ inhibition (\%)

\begin{tabular}{lllllllll}
\hline \multicolumn{7}{c}{ Dosage $\left(\mathrm{mg} \mathrm{L}^{-1}\right)$} \\
\cline { 2 - 9 } Scale inhibitors & 2 & 4 & 6 & 8 & 10 & 12 & 14 & 16 \\
\hline ML15 & 14.3 & 42.1 & 75.8 & 97.8 & 98.1 & 98.5 & 97.8 & 99.1 \\
T-225 & 12.5 & 35.2 & 55.2 & 67.9 & 75.7 & 77.3 & 82.2 & 80.9 \\
HPMA & 10.3 & 18.5 & 31.9 & 46.7 & 63.3 & 66.8 & 68.7 & 67.5 \\
PAA & 14.0 & 33.6 & 45.2 & 58.6 & 61.1 & 63.9 & 71.6 & 69.8 \\
PESA & 13.8 & 37.9 & 61.5 & 74.5 & 79.3 & 82.6 & 85.8 & 84.7 \\
& & & & & & & & \\
\hline
\end{tabular}

MA-APEM-APTA was also weakly inferior to ML15, only $79.6 \%$ inhibition were obtained at the concentration of $6 \mathrm{mg} \mathrm{L}^{-1}{ }^{6}$

\subsection{ML $n$ copolymer modify the formation of $\mathrm{CaCO}_{3}$}

The presence of antiscalants influences not only the growth but also morphology of calcium carbonate crystals. Fig. 8 shows the SEM images of calcium carbonate crystals in the absence and in the presence of $4 \mathrm{mg} \mathrm{L}^{-1} \mathrm{ML} n(n=5,10,15)$. It can be seen that in the absence of inhibitor, $\mathrm{CaCO}_{3}$ exhibits regular rhombohedron shape with average particle size of about 10-30 $\mu \mathrm{m}$ (Fig. 6a). They also had a glossy surface and compact structure. This indicated that the $\mathrm{CaCO}_{3}$ crystals in the blank sample without scale inhibitor were mainly composed of calcite, which was the most thermodynamically stable form of $\mathrm{CaCO}_{3}$ crystal. And in the presence of $\operatorname{ML} n(n=5,10,15)$ (Fig. $6 \mathrm{~b}-\mathrm{d})$, the $\mathrm{CaCO}_{3}$ crystals loses its sharp edges, and the morphology has been modified from rhombohedron forms to the smaller fragments with relatively loose accumulation. Furthermore, the bigger $n$ is, the stronger the influence is on calcium carbonate crystal morphology and size. The reason can be attributed to MLn copolymer containing long polyethylene glycol (PEG) chain, except for the effect of lattice distortion, ML $n$ can enclose the grain and retard the outgrowth of $\mathrm{CaCO}_{3}$ crystal to form the smooth scale. ${ }^{15}$ So the bigger $n$ is, the longer PEG chain can easier enclose the grain and retard the outgrowth of $\mathrm{CaCO}_{3}$ crystal.

The $\mathrm{CaCO}_{3}$ precipitated phases are identified by XRD, and the spectra are shown in Fig. 7. In the absence of the MLn copolymer, calcite is the main crystal form [Fig. 7(a)]. As indicated in Fig. $7(\mathrm{~b}-\mathrm{d})$, in the presence of the $\operatorname{ML} n(n=5,10,15)$ copolymer, there are a number of vaterite crystals interlarding. It is well known that calcite is the most thermodynamically stable, and vaterite is the least stable form in the three polymorphic forms of $\mathrm{CaCO}_{3}{ }^{1,16}$ Vaterite is the initial phase formed when $\mathrm{CaCO}_{3}$ supersaturated; calcite can be formed from the transformation of aragonite or vaterite in the absence of

Table 2 The inhibition of scale formation of ML15 $\left(8 \mathrm{mg} \mathrm{L}^{-1}\right)$

\begin{tabular}{|c|c|c|c|c|c|c|c|c|}
\hline \multirow{2}{*}{$\frac{\text { Ions }}{\mathrm{Ca}^{2+}}$} & \multicolumn{8}{|c|}{ Concentration $\left(\mathrm{mg} \mathrm{L}^{-1}\right)$} \\
\hline & 240 & 240 & 240 & 240 & 240 & 240 & 240 & 240 \\
\hline $\mathrm{Mg}^{2+}$ & 10 & 20 & 30 & 40 & 50 & 60 & 80 & 100 \\
\hline $\mathrm{SO}_{4}{ }^{2-}$ & 100 & 200 & 300 & 400 & 500 & 1000 & 1500 & 2000 \\
\hline $\mathrm{CO}_{3}^{2-}$ & 732 & 732 & 732 & 732 & 732 & 732 & 732 & 732 \\
\hline Inhibition of scale formation (\%) & 98.3 & 96.7 & 94.8 & 93.2 & 91.1 & 89.2 & 85.7 & 80.5 \\
\hline
\end{tabular}




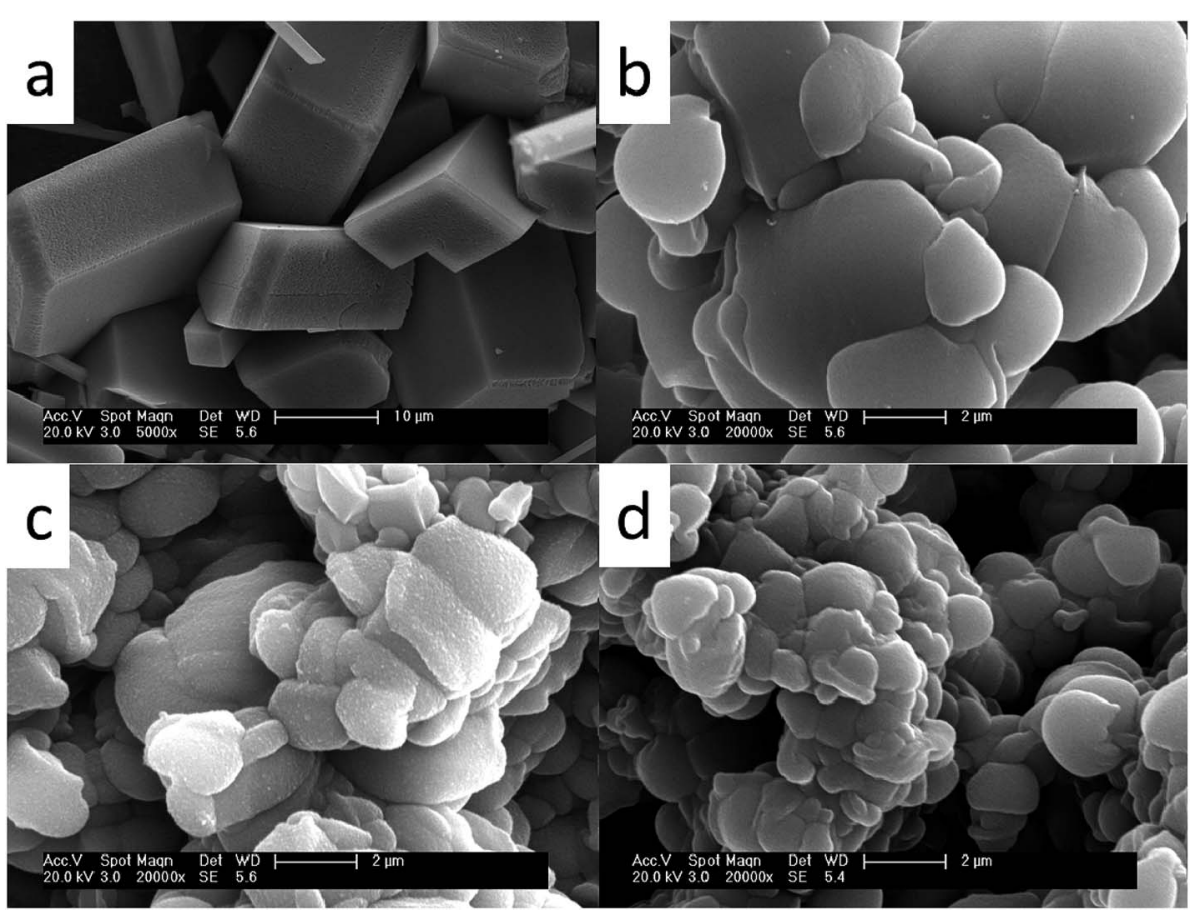

Fig. 6 SEM images of calcium carbonate crystals (a) in the absence of $M L n$ copolymer; (b-d) in the presence of $M L n$ copolymer; (b) $n=5$, (c) $n=$ 10, (d) $n=15$.

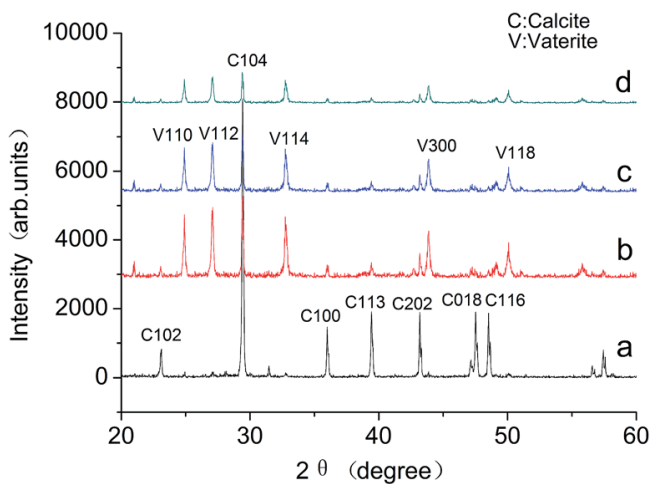

Fig. 7 The XRD pattern of the $\mathrm{CaCO}_{3}$ crystals (a) in the absence of MLn copolymer; (b-d) in the presence of MLn copolymer; (b) $n=5$, (c) $n=$ 10, (d) $n=15$.

inhibitors. ${ }^{17}$ Although calcite has the greatest thermodynamic stability under ambient conditions, the thermodynamically less stable aragonite and/or vaterite phase may be stabilized under certain conditions of temperature or in the presence of inhibitors. ${ }^{18}$ Furthermore, with the increase of $n$ value, the diffraction peaks of calcite and vaterite were decreased. The crystallinity of calcium carbonate decreased significantly. The results of XRD also gave consistent results as SEM.

\subsection{The mechanism of calcium carbonate inhibition}

ML $n$ is a structurally well-defined biblock copolymer, depicted in Fig. 8a, one block is PMA, and the other is PEG segments. Both PMA and PEG segments are hydrophilic blocks and exist

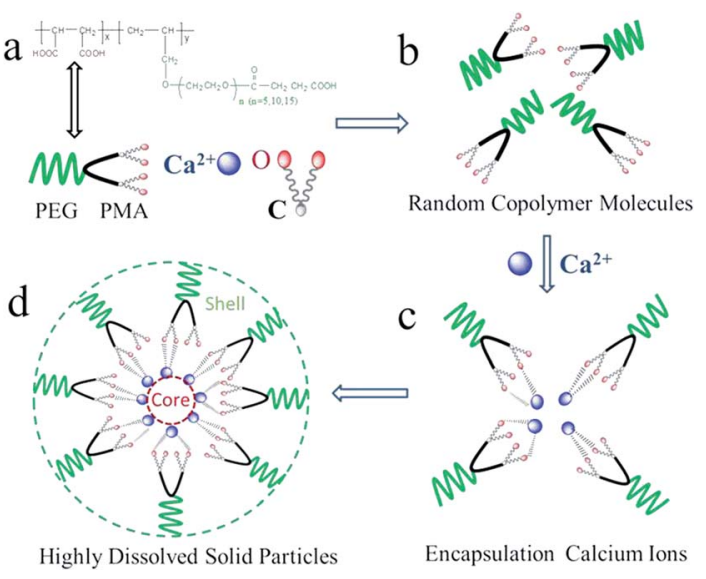

Fig. 8 Encapsulation calcium irons route via carboxyl groups.

randomly in water (Fig. 6b). When calcium ions are added into ML $n$ solutions, carboxyl groups in MLn matrixes can recognize and encapsulate or react with positively charged calcium ions either in solutions or on the surface of inorganic minerals, such as $\mathrm{CaCO}_{3} \cdot{ }^{19,20}$ Encapsulation between calcium ions and carboxyl groups, leads to the spontaneous formation of MLnCa complexes (Fig. 6c). At the same time, water-compatible PEG segments, surrounding the surfaces of $\mathrm{CaCO}_{3}$ crystal embryos, are stable toward aqueous phase because of their high hydrophilic properties (Fig. 6d). ${ }^{21-23}$ Thus, $\mathrm{CaCO}_{3}$ embryos incorporate into the polymer matrix of MLn, and they are coated with double layers of PMA (inner layer) and PEG (outer layer). As a consequence, the aggregation of $\mathrm{CaCO}_{3}$ solid particles is blocked. 


\section{Conclusions}

A novel phosphorous free and non-nitrogen antiscalant for calcium carbonate inhibition, denoted as MLn, was synthesized. It is believed to represent a potentially new environmentally safe water treatment agent suitable for cooling water systems.

ML15, ML10 and ML5 possess excellent calcium carbonate inhibition, approximately 98,91 and $82 \%$ at threshold dosage of $8 \mathrm{mg} \mathrm{L}^{-1}$, respectively. ML15 has the best inhibition because of possessing the greatest degree of polymerization among $\operatorname{ML} n$ ( $n=$ $5,10,15)$. ML15 maintains most of its calcium carbonate inhibition under the conditions of solution $\mathrm{pH} 7-10, \mathrm{HCO}_{3}{ }^{-}$concentration (732-1647 $\mathrm{mg} \mathrm{L}^{-1}$ ) and at levels of $0-10 \mathrm{mg} \mathrm{L}^{-1}$ iron ions in aqueous solutions. ML15 provides unexceptionable calcium carbonate inhibition under conditions of water with a much higher hardness. The inhibition of ML15 was still above $80 \%$ when the concentrations of $\mathrm{Mg}^{2+}, \mathrm{PO}_{4}{ }^{3-}$ and $\mathrm{SO}_{4}{ }^{2-}$ ions in solutions are $100 \mathrm{mg} \mathrm{L}^{-1}, 100 \mathrm{mg} \mathrm{L}^{-1}$ and $2000 \mathrm{mg} \mathrm{L}^{-1}$, respectively.

Compared to PAA, HPMA, PESA and T-225, ML15 possessing PEG, shows a superior inhibitory efficiency. The inhibition mechanism is proposed that encapsulation or interaction happened between PEG and $\mathrm{Ca}^{2+}$ and the core-shell structure is formed.

SEM and XRD images indicate that ML15 changes highly the morphology and size of calcium carbonate crystals during the inhibition process. The crystallization of $\mathrm{CaCO}_{3}$ in the absence of ML $n$ was rhombohedral calcite crystal, whereas a mixture of calcite with vaterite crystals was found in the presence of the copolymer.

\section{Acknowledgements}

The National Natural Science Foundation of China (No. 51077013), The National Natural Science Foundation of China (No. 21506102), China Postdoctoral Science Foundation (No. 2014M560381), Jiangsu Planned Projects for Postdoctoral Research Funds (No. 1401033B), The Municipal Key Subjects of Environmental Science and Engineering, Nanjing Xiaozhuang University, Nanjing. University Student Technology Innovation Project of Jiangsu Province (No. 201611460008Z). University Student Technology Innovation Project of Jiangsu Province (School-enterprise cooperation) (201611460085H).

\section{References}

1 A. G. Xyla, J. Mikroyannidis and P. G. Koutsoukos, J. Colloid Interface Sci., 1992, 153, 537-551.
2 L. C. Wang, K. Cui, L. B. Wang, H. X. Li, S. F. Li, Q. l. Zhang and H. B. Liu, Desalination, 2016, 379, 75-84.

3 G. Liu, M. Xue, Q. Liu and Y. Zhou, Des. Monomers Polym., 2017, 2, 397-405.

4 G. Liu, J. Huang, Y. Zhou, Q. Yao, L. Ling, C. Fu, W. Wu, W. Sun and Z. Hu, Front. Environ. Sci. Eng., 2015, 9, 545553.

5 Y. Liu, C. Zou, C. Li, L. Lin and W. Chen, Desalination, 2016, 377, 28-33.

6 H. Wang, Y. Zhou, Q. Yao, S. Ma, W. Wu and W. Sun, Desalination, 2014, 340, 1-10.

7 P. Zhang, D. Shen, G. Ruan, A. T. Kan and M. B. Tomson, J. Ind. Eng. Chem., 2017, 45, 366-374.

8 A. A. Younes, H. H. El-Maghrabi and H. R. Ali, J. Hazard. Mater., 2017, 334, 1-9.

9 A. Khormali, D. G. Petrakov and R. N. Moghaddam, J. Pet. Sci. Eng., 2017, 153, 257-267.

10 C. Fu, Y. Zhou, G. Liu, J. Huang, W. Sun and W. Wu, Ind. Eng. Chem. Res., 2011, 50, 10393-10399.

11 L. Ling, Y. Zhou, J. Huang, Q. Yao, G. Liu, P. Zhang, W. Sun and W. Wu, Desalination, 2012, 304, 33-40.

12 Water Treatment Reagent Unit of Standardization Research Institute of Chemical Industry of China, Application Guidebook on Water Quality of Circulation Cooling Water and Standard of Water Treatment Reagents (in Chinese), Chemical Industry Press, Beijing, 2003.

13 G. Liu, M. Xue, Q. Liu and Y. Zhou, Clean Technol. Environ. Policy, 2017, 19, 917-924.

14 Z. Amjad, Langmuir, 1991, 7, 600-603.

15 L. F. Greenlee, F. Testa, D. F. Lawler, B. D. Freeman and P. Moulin, Water Res., 2010, 44, 2957-2969.

16 H. Wei, Q. Shen, H. H. Wang, Y. Y. Gao, Y. Zhao, D. F. Xu and D. J. Wang, J. Cryst. Growth, 2007, 303, 537-545.

17 D. S. Kim and C. K. Lee, Appl. Surf. Sci., 2002, 202, 15-23.

18 P. K. Ajikumar, B. J. Michellelow and S. Valiyaveettil, Surf. Coat. Technol., 2005, 198, 227-230.

19 S. H. Yu, H. Colfen and M. Antonietti, J. Phys. Chem. B, 2003, 107, 7396-7405.

20 A. Harada and K. Kataoka, J. Am. Chem. Soc., 1999, 121, 92419242.

21 A. Harada and K. Kataoka, Macromolecules, 1998, 31, 288294.

22 A. Harada and K. Kataoka, Langmuir, 1999, 15, 42084212.

23 J. Rudloff and H. Colfen, Langmuir, 2004, 20, 991-996. 